\title{
O FUNDEB PERMANENTE EM TEMPOS DE DESCONSTRUÇÃO E DESFAZIMENTO: MOBILIZAÇÃO E UM BASTA VEEMENTE
}

PERMANENT FUNDEB IN TIMES OF DECONSTRUCTION AND DISMANTLING: MOBILIZATION AND A VEHEMENT ENOUGH

\author{
FUNDEB PERMANENTE EN TIEMPOS DE DECONSTRUCCIÓN Y \\ DESMANTELAMIENTO: MOVILIZACIÓN Y UN BASTA VEHEMENTE
}

\author{
Nelson Cardoso Amaral ${ }^{1}$ \\ SANDra Maria Zákia Lian Souza ${ }^{2}$ \\ SALOMÃo BARros Ximenes 3 \\ IVANy Rodrigues PINO ${ }^{4}$ \\ Luana Costa Almeida ${ }^{5}$ \\ Pedro Goergen ${ }^{6}$ \\ Celso João Ferretti ${ }^{7}$ \\ Antonio Álvaro Soares Zuin ${ }^{8}$ \\ Carmen Sylvia Vidigal Moraes ${ }^{9}$ \\ Adriana Dragone Silveira ${ }^{10}$ \\ Licínio Carlos Viana da Silva Lima ${ }^{11}$ \\ XaVier Rambla ${ }^{12}$ \\ Anderson Ricardo Trevisan ${ }^{13}$ (D)
}



hegamos ao ano de 2021 ainda imersos na pandemia provocada pelo coronavírus (SARS-CoV-2) que atingiu o planeta em 2019 e se expandiu em 2020, causando danos à saúde de milhões de pessoas e resultando na morte de centenas de milhares delas. Além disso, a pandemia provocou a erosão das economias da maioria dos países, o que pode levar anos para que ocorra uma recuperação segura. No Brasil, a pandemia se fez presente a partir de fevereiro/março de 2020, e estávamos, então, no início do segundo ano do governo Bolsonaro. Em janeiro de 2021, no Brasil, o coronavírus já havia contaminado quase 8 milhões de pessoas e o número de mortes ultrapassava 200.000.

Em um Editorial da E\&S de 2018, intitulado "A Educação no Atual Cenário Político Econômico Mundial: A Disputa Eleitoral e os Retrocessos na Educação", dizíamos que as eleições de 2018 estavam

1.Universidade Federal de Goiás - Goiânia (GO), Brasil. E-mail: nelsoncardosoamaral@gmail.com

2.Universidade de São Paulo - Faculdade de Educação - São Paulo (SP), Brasil. E-mail: sanzakia@usp.br

3.Universidade Federal do ABC - Centro de Engenharia, Modelagem e Ciências Sociais Aplicadas - São Bernardo do Campo (SP), Brasil. E-mail: salomaoximenes@gmail.com

4.Universidade Estadual de Campinas - Faculdade de Educação/Centro de Estudos Educação e Sociedade - Campinas (SP), Brasil. E-mail: ivanypino@gmail.com

5.Universidade Federal de São Carlos - Departamento de Teorias e Práticas Pedagógicas - São Carlos (SP), Brasil. E-mail: luana.ees@gmail.com

6.Universidade de Sorocaba - Sorocaba (SP), Brasil. E-mail: pedro.goergen@hotmail.com

7.Centro de Estudos Educação e Sociedade - Campinas (SP), Brasil. E-mail: celsojoaoferretti@gmail.com

8.Universidade Federal de São Carlos - Departamento de Educação - São Carlos (SP), Brasil. E-mail: dazu@ufscar.br

9.Universidade de São Paulo - Faculdade de Educação - São Paulo (SP), Brasil. E-mail: moraescs@usp.br

10.Universidade Federal do Paraná - Setor de Educação - Curitiba (PR), Brasil. E-mail: adrianadragonesilveira@gmail.com

11.Universidade do Minho - Instituto de Educação - Departamento de Ciências Sociais da Educação - Braga, Portugal. E-mail: llima@ie.uminho.pt

12.Universitat Autònoma de Barcelona - Barcelona, Espanha. E-mail: xavier.rambla@uab.cat

13.Universidade Estadual de Campinas - Campinas (SP), Brasil. E-mail: detrevis@unicamp.br 
prestes a ocorrer e que era preciso estar atentos aos programas apresentados pelos candidatos e aos seus "compromissos com a educação pública" (EDITORIAL, 2018).

Atingimos a metade do governo Bolsonaro. É um bom momento para voltarmos ao seu programa de governo, apresentado em 2018, e realizarmos uma análise das ações que foram implementadas pelos grupos que assumiram o Governo Federal (LEHER, 2019).

Destaca-se, no programa em questão, que se intitula "O Caminho da Prosperidade", a afirmação de que "Nos últimos 30 anos o marxismo cultural e suas derivações com o gramcismo se uniu às oligarquias corruptas para minar os valores da Nação e da família brasileira” (PROGRAMA..., 2018). A Constituição Federal de 1988 (CF-1988) está incluída nesse período de trinta anos e, portanto, segundo a visão desses grupos, teria sofrido a interferência do chamado "marxismo cultural", que, em seu combate, quase "espectral", "mente, deforma, difama, acusa sem critério, procura punir e estigmatizar, valendo-se da simplificação grosseira e da pressão dos aparatos estatais” (NOGUEIRA, 2019).

O que se pode concluir dessa afirmação do programa? Que desde a CF-1988, fim do governo de José Sarney, até o governo de Michel Temer, passando por Fernando Henrique Cardoso, Luiz Inácio Lula da Silva e Dilma Rousseff, o país teria sido dominado por esse "pensamento"? Se essa é a visão dos grupos de apoio a Jair Bolsonaro, que comportamento se poderia esperar deles, a partir do início de 2019, quando assumiram o governo?

Parece-nos que a resposta para o comportamento foi dada pelo próprio presidente, em Washington, no dia 17 de março de 2019, quando afirmou: “Nós temos é que desconstruir muita coisa. Desfazer muita coisa para depois começarmos a fazer. Que eu sirva para que, pelo menos, eu possa ser um ponto de inflexão, já estou muito feliz." Concluiu o presidente: "O nosso Brasil caminhava para o socialismo, para o comunismo" (LÁZARO, 2019).

Interligando os conteúdos do programa de governo e a afirmação supracitada, talvez seja possível começar a compreender os motivos de existirem tantas iniciativas que procuram alterar a CF-1988, seja por meio de Propostas de Emendas à Constituição (PEC), seja por ações que não respeitam os termos estabelecidos na Lei Maior brasileira - ações desencadeadas tanto pelos grupos no Governo Federal quanto por parte dos membros do Congresso Nacional, em geral, aliados desses grupos.

Há evidências de que, nesses dois anos, procurar alterar a Constituição, ao mesmo tempo desrespeitando-a, foi a opção encontrada para atingir os objetivos de descontruir e desfazer. É notória a quantidade de vezes em que o Supremo Tribunal Federal (STF) se tornou/torna o protagonista de discussões políticas, econômicas e sociais; somente o "Conselho Federal da OAB [Ordem dos Advogados do Brasil] acionou o STF 80 vezes nos dois primeiros anos de governo Bolsonaro, média de uma ação por semana” (AMADO, 2020).

A "congestação" de medidas autoritárias e inconstitucionais de Bolsonaro e, em muitos casos, a capacidade de barrá-las antes que produzam efeitos, demonstra, por outro lado, a capacidade de resistência e enfretamento do campo democrático. Na área da educação, um exemplo foi a suspensão, pelo STF, do Decreto n. 10.502, de 30 de setembro de 2020, que propunha a desestruturação da política nacional de educação inclusiva. Não há, portanto, livre trânsito dos setores bolsonaristas - há resistências e mesmo conquistas durante esse período, creditadas à luta social, por afirmação de direitos historicamente conquistados.

Um caso emblemático, que exemplifica esse cenário, foi o processo de tramitação da Proposta de Emenda Constitucional n. 15/2015 (PEC n. 15/2015) para tornar o Fundo de Manutenção e Desenvolvimento da Educação Básica e de Valorização dos Profissionais da Educação (Fundeb) permanente e, em segundo lugar, a tramitação de Projeto de Lei n. 4372, de 2020 (PL n. 4372/2020), que efetivaria a regulamentação do Fundeb. A PEC n. 15/2015, depois de aprovada, tornou-se a Emenda Constitucional n. 108, de 26 de agosto 
de 2020 (EC-108) e o PL n. 4372/2020 transformou-se na Lei n. 14.113, de 25 de dezembro de 2020, quando foi aprovado.

O Fundeb, até então regulamentado pela Lei n. 11.494, de 20 de junho de 2007, estabelecia que os fundos estaduais e distrital teriam vigência até o dia 31 de dezembro de 2020. A continuidade dos fundos, portanto, dependeria da aprovação da PEC n. 15/2015; sem isso, muitos municípios com baixa arrecadação diante do número de alunos de sua rede de ensino não teriam condições de desenvolver suas atividades educacionais, desde o pagamento dos salários dos trabalhadores até a manutenção das atividades de sala de aula. A situação se mostraria ainda mais grave em face da queda de arrecadação e, consequentemente, de recursos vinculados à educação nos estados e municípios.

A PEC n. 15/2015 propôs que o Fundeb fosse constitucionalizado e a sua discussão envolveu a sociedade brasileira por meio de audiências públicas em que se verificaram a oportunidade da constitucionalização e os termos da proposta apresentada. Nos anos de 2019 e 2020, o Ministério da Educação, com a posse do governo Bolsonaro, desprezou a discussão que estava sendo realizada. Uma interpretação possível para o fato é que os grupos que assumiram o Governo Federal eram contrários à continuidade dessa política pública de subvinculação de recursos constitucionais.

Essa possibilidade de interpretação se sustenta em declarações do Ministro da Economia quando, em 10 de março de 2019, afirmou a possibilidade de acabar com as vinculações existentes na Constituição: "são os representantes do povo reassumindo o controle orçamentário. É a desvinculação, a desindexação, a desobrigação e a descentralização dos recursos das receitas e das despesas” (FERNANDES; FUCS; AGOSTINI, 2019). Essa proposta, caso se efetivasse, resultaria na extinção do Fundeb, por constituir subvinculação de recursos de impostos vinculados constitucionalmente à educação, em seu artigo 212.

Para fazer frente à possibilidade de desvinculação, houve a mobilização de diversos setores da sociedade, em especial aqueles associados à educação e à saúde, o que fez o Governo Federal alterar essa proposição do Ministro da Economia e admitir a continuidade das duas vinculações, alterando, porém, substancialmente o seu formato de maneira perversa, o que poderia colocar, se aprovada, uma disputa entre essas duas áreas pelos recursos públicos. Isso ocorreu no bojo da Proposta de Emenda à Constituição n. 188/2019 (PEC n. 188/2019-Senado), apresentada ao Senado no dia 5 de novembro de 2019 e apelidada de PEC do pacto federativo.

A possibilidade da vinculação de impostos para a educação e para a saúde está prevista no artigo 167, inciso IV, da CF-1988, quando estabelece que são vedados:

[...] a vinculação de receita de impostos a órgão, fundo ou despesa, ressalvadas a repartição do produto da arrecadação dos impostos a que se referem os arts. 158 e 159, a destinação de recursos para as ações e serviços públicos de saúde, para manutenção e desenvolvimento do ensino [...] (BRASIL, 1988, inciso IV, art. 167, grifos nossos).

A PEC n. 188/2019-Senado propunha a alteração do inciso IV, nos seguintes moldes:

[...] a vinculação das receitas públicas a órgão, fundo ou despesa, ressalvadas: a) as oriundas da arrecadação de taxas, de contribuições, das doações, dos empréstimos compulsórios e das receitas de capital; b) a repartição entre os entes federados do produto da arrecadação das receitas a que se referem os $\$ \$ 1^{\circ}$ e $3^{\circ}$ do art. 20, o inciso III do parágrafo único do art. 146 e os arts. 157, 158 e 159, bem como a destinação a que se refere o art. 159, I, "c", desta Constituição; c) as repartições com Estados e Municípios dos recursos financeiros oriundos de concessão florestal; d) as repartições com Municípios e Distrito Federal dos recursos da 
cobrança de taxa de ocupação, foro e laudêmio; e) a prestação de garantias às operações de crédito por antecipação de receita, previstas no art. $165, \$ 8^{\circ}$; e f) a permitida pelo $\$ 4^{\circ}$ deste artigo (BRASIL, 2019b).

Verifica-se que a ressalva relativa aos recursos financeiros a ser aplicados em educação e saúde seria retirada do artigo 167 da CF-1988. Pode-se concluir que essa alteração já preparava a completa desvinculação dos recursos da educação e da saúde como declarara o Ministro da Economia. A mobilização social contra essa possibilidade, como já afirmamos, teve o efeito da manutenção dos artigos 198 e 212 da Constituição, que prescrevem a vinculação dos recursos para a saúde e para a educação, respectivamente. O grande problema, entretanto, encontra-se na PEC n. 188/2019-Senado, que prevê a inclusão do $\$ 7^{\circ}$ no artigo 198 , permitindo que sejam aplicados valores em saúde maiores que o mínimo, desde que aplicado em educação um volume de recursos menor que o mínimo:

[...] fica autorizada, na elaboração da proposta orçamentária e na respectiva execução, a dedução do montante aplicado na manutenção e desenvolvimento do ensino que exceder o mínimo aplicável nos termos do art. 212, caput, desta Constituição (BRASIL, 2019b, grifos nossos).

O caminho inverso ficou estabelecido no $\$ 7^{\circ}$ do artigo 212 :

[...] fica autorizada, na elaboração da proposta orçamentária e na respectiva execução, a dedução do montante aplicado em ações e serviços públicos de saúde que exceder o mínimo aplicável, nos termos do art. 198, $\$ 2^{\circ}$, desta Constituição (BRASIL, 2019b, grifos nossos).

Se aprovada, essa PEC concretizará uma vinculação acoplada educação-saúde, pois induzirá a uma disputa entre esses dois setores fundamentais para o desenvolvimento do país e trará enormes prejuízos para a população brasileira, uma vez que são setores subfinanciados em comparação com países que atingiram graus de desenvolvimento humano maiores que os brasileiros.

Caso aprovada essa proposta, não haverá, entretanto, alteração na subvinculação do Fundeb. As consequências serão que os estados, Distrito Federal e municípios teriam uma limitação para deslocar recursos da educação para a saúde, já que isso só poderia se realizar com os percentuais de impostos não associados ao Fundeb - mais uma razão para afirmar sua importância.

No caso da União, seria preciso, em primeiro lugar, cumprir suas obrigações constitucionais relativas ao financiamento das “instituições de ensino públicas federais" (BRASIL, 1988, \$1ª art. 211), exercer "função redistributiva e supletiva, de forma a garantir equalização de oportunidades educacionais e padrão mínimo de qualidade do ensino mediante assistência técnica e financeira aos Estados, ao Distrito Federal e aos Municípios [...]" (BRASIL, 1988, \$1º, art. 211) e promover o repasse da Complementação da União ao Fundeb (BRASIL, 2020a). Além disso, a União deverá “assegurar, anualmente, em seu Orçamento Geral, recursos suficientes para manutenção e desenvolvimento das instituições de educação superior por ela mantidas" (BRASIL, 1996, art. 55). Somente após cumprir essas obrigações a União poderia transferir recursos financeiros para a saúde, caso o total desses compromissos não ultrapassasse os $18 \%$ vinculados pelo artigo 212 da CF-1988. O risco iminente, no caso da educação superior federal, é o de proceder a um grande arrocho salarial de professores e servidores técnico-administrativos, diminuindo os recursos aplicados em universidades, institutos federais e centros tecnológicos, para que fossem então destinados à saúde. Cabe aqui uma pergunta: a proposta do Future-se (BRASIL, 2020c), que discutimos no Editorial "Reafirmar a Defesa do Sistema de Ciência, Tecnologia e Ensino Superior Público Brasileiro" (EDITORIAL, 2019), em que se 
colocariam essas instituições à procura de recursos na sociedade, já não seria um componente da estratégia para essa redução?

Não se pode esquecer, em complemento, que mesmo as vinculações à saúde e à educação hoje afirmadas, respectivamente, nos artigos 198 e 212 da Constituição, encontram-se suspensas por força da Emenda Constitucional n. 95, de 2016 (EC-95), a qual estabelece o chamado teto de gastos públicos federais. Para isso, a EC-95 suspende a aplicação dos artigos citados por vinte anos, substituindo as vinculações por meras atualizações inflacionárias do mínimo constitucional aplicado no exercício de 2017. Trata-se de um "Estado de Sítio Fiscal" (PINTO; XIMENES, 2018), de flagrante inconstitucionalidade, já questionada em diversas ações no STF.

O caminho da desvinculação total, escolhido inicialmente pelo Governo Federal e que liquidaria com a ideia do Fundeb, não logrou êxito, e a discussão sobre a PEC n. 15/2015 evolui na Câmara dos Deputados, sem que o governo Bolsonaro estabelecesse uma interlocução. Na última hora, no entanto, o governo se propôs a participar da discussão e, procurando utilizar o fato de que os recursos associados ao Fundeb não são computados nas restrições existentes na EC-95, pretendia "desviar" parte dos recursos do fundo para pagar um programa assistencial a ser implantado por meio de "voucher-creche" na rede privada. Essa estratégia foi evidenciada quando se adiou a votação da PEC na Câmara dos Deputados:

A votação do Fundo de Manutenção e Desenvolvimento da Educação Básica e de Valorização dos Profissionais da Educação (Fundeb) foi adiada para a terça-feira (21) na Câmara dos Deputados [...]. A mudança ocorre porque o ministro da Secretaria de Governo, Luiz Eduardo Ramos, tenta convencer líderes partidários, desde a manhã desta segunda-feira (20), a repartir o dinheiro do fundo com um programa assistencial do governo. O governo quer abocanhar $\mathrm{R} \$ 6$ bilhões do fundo para bancar um "voucher-creche" a ser destinado a beneficiários do Renda Brasil, um programa ainda inexistente que o Ministério da Economia diz se assemelhar ao Bolsa Família (GIMENES, 2020).

Também nesse caso, houve uma rápida mobilização social contra a proposta e, no fim dessa negociação, de que já participava o Governo Federal, elevou-se o percentual de complementação da União ao Fundeb de 20 para 23\%, com a condição de que parte desses recursos obrigatoriamente se dirigisse para a educação infantil sem, entretanto, associá-lo a qualquer programa governamental (BRASIL, 2015).

Esperava-se, na continuidade, que se descortinasse a estratégia governamental para essa elevação de três pontos percentuais nos recursos da complementação da União. Ela se explicitou na votação da PEC n. 15/2015, quando foram apresentados destaques que propunham a possibilidade de a CF-1988 admitir que recursos públicos fossem destinados às escolas privadas, os quais foram majoritariamente negados na votação.

Finalmente, a PEC foi aprovada na Câmara dos Deputados por ampla maioria e no Senado por unanimidade. A homologação ocorreu no dia 26 de agosto de 2020 pelo Congresso Nacional, tornando-se a Emenda Constitucional n. 108 (EC-108), que constitucionalizou o Fundeb.

Apesar de ter sido uma vitória da sociedade brasileira, o documento apresenta aspectos que limitam as possibilidades de cumprimento do direito à educação de qualidade para todos, ao prever uma complementação da União ainda insuficiente para que seja implantado um valor Custo-Aluno Qualidade (CAQ), que possa realmente provocar uma verdadeira "revolução" educacional no Brasil. Também a sua implementação, até o ano de 2026, é um prazo muito longo, que impedirá o pleno cumprimento das metas do PNE (2014-2024). Além disso, a emenda vinculou parte dos recursos financeiros a condicionalidades, como melhoria de gestão, melhoria da aprendizagem, evolução em indicadores a serem definidos etc. Esse tipo de 
vinculação contraria o que se pode considerar os princípios de uma política de fundos que foram estabelecidos por Anísio Teixeira em "Bases Preliminares para o Plano de Educação Referente ao Fundo Nacional de Ensino Primário”, artigo publicado em 1962 (TEIXEIRA, 1962): amenizar a desigualdade econômica e cultural existentes entre os municípios brasileiros; e fixar um "custo-padrão" da educação que deveria ser financiada com recursos financeiros da União, estados, Distrito Federal e municípios.

Há que se destacar os seguintes pontos, reconhecidos como avanços tanto pela Associação Nacional de Pesquisa em Financiamento da Educação (Fineduca) quanto pela Campanha Nacional pelo Direito à Educação:

- O aumento da complementação da União de $10 \%$ para $23 \%$, com recursos novos preservando o Salário-Educação;

- A constitucionalização do Custo Aluno-Qualidade (CAQ), como parâmetro para qualidade adequada da educação e como mecanismo de controle social, melhoria da gestão, segurança jurídica, fazendo avançar a justiça federativa no Brasil;

- A incorporação do Sistema Nacional de Avaliação da Educação Básica (Sinaeb) como política de avaliação que inclui, mas supera as avaliações de larga escala;

- Sua distribuição pelo sistema híbrido - por meio do Valor Aluno Ano dos Fundos (VAAF) e Valor Aluno Ano Total (VAAT) - sendo mais equitativo, mas sem desestruturar grandes redes públicas do Norte e Nordeste do país;

- A destinação de pelo menos 70\% dos recursos à remuneração dos profissionais da educação básica, de forma a valorizar todos os profissionais da educação;

- Proibição do desvio dos recursos de Manutenção e Desenvolvimento do Ensino para o pagamento de aposentadorias; e

- Uso do recurso público exclusivamente para a educação pública (FINEDUCA; CAMPANHA, 2020).

Para que o Fundeb, agora constitucional, se tornasse operacional era necessário um conjunto de regulamentações (BRASIL, 2020a). Para que isso pudesse ocorrer, foi a votação na Câmara dos Deputados o Projeto de Lei n. 4372/2020 (PL n. 4372/2020) e, nesse momento, voltou-se à carga a discussão sobre os recursos se dirigirem ao setor privado, apesar de essa questão já ter sido vencida quando da discussão da PEC n. 15/2015, como demonstrado em Nota Técnica emitida por 303 procuradores, professores, juízes, promotores e outros profissionais do serviço público (PINTO et al., 2020).

Constatou-se, com surpresa, a aprovação de dispositivo que permitisse a "instituições comunitárias, confessionais ou filantrópicas sem fins lucrativos e conveniadas com o poder público" e também ao chamado Sistema S receberem recursos financeiros do Fundeb.

O encaminhamento aprovado provocou novamente grande mobilização social, que resultou, no Senado, no retorno do texto original apresentado na Câmara, o qual não continha possibilidades para o financiamento desses setores. Retornando à Câmara dos Deputados, finalmente, o texto foi aprovado sem nenhuma alteração em relação ao do Senado.

Aprovado, o PL n. 4372 se transformou na Lei n. 14.113, de 25 de dezembro de 2020, que "Regulamenta o Fundo de Manutenção e Desenvolvimento da Educação Básica e de Valorização dos Profissionais da Educação (Fundeb), de que trata o art. 212-A da Constituição Federal; revoga dispositivos da Lei n. 11.494, de 20 de junho de 2007; e dá outras providências” (BRASIL, 2020b). 
Entretanto, há que se mobilizar novamente, tendo em vista a possibilidade de recursos públicos se dirigirem ao setor privado, pois a PEC n. 188/2019-Senado propõe mudanças constitucionais que procuram exatamente alterar o artigo 213 da Constituição, o qual, em conjunto com o artigo $6^{\circ}$ da Emenda Constitucional n. 59/2009 (BRASIL, 2009), foi âncora jurídica para impedir o ímpeto privatista de grupos no Governo Federal e seus aliados.

$\mathrm{O}$ artigo 213 estabelece que:

Os recursos públicos serão destinados às escolas públicas, podendo ser dirigidos a escolas comunitárias, confessionais ou filantrópicas, definidas em lei, que:

I - comprovem finalidade não lucrativa e apliquem seus excedentes financeiros em educação;

II - assegurem a destinação de seu patrimônio a outra escola comunitária, filantrópica ou confessional, ou ao poder público, no caso de encerramento de suas atividades (BRASIL, 1988, art. 213).

e o $\$ 1^{\circ}$ desse artigo afirma que:

Os recursos de que trata este artigo poderão ser destinados a bolsas de estudo para o Ensino Fundamental e Médio, na forma da lei, para os que demonstrarem insuficiência de recursos, quando houver falta de vagas e cursos regulares da rede pública na localidade da residência do educando, ficando o poder público obrigado a investir prioritariamente na expansão de sua rede na localidade (BRASIL, 1988, $\$ 1^{\circ}$, art. 213, grifos nossos).

A PEC 188-2019/Senado propõe alterar esse $\$ 1^{\circ}$ para:

Os recursos de que trata este artigo poderão ser destinados a bolsas de estudo para o ensino básico, na forma da lei, para os interessados inscritos e selecionados que demonstrarem insuficiência de recursos, quando houver instituições cadastradas, segundo requisitos definidos em lei, na localidade da residência do educando (BRASIL, 2019b).

Portanto, o poder público deixa de ter a obrigação de "investir prioritariamente na expansão de sua rede na localidade" quando "houver falta de vagas e cursos regulares na rede pública na localidade da residência do educando", podendo, para isso ofertar, "bolsas de estudo para o ensino básico [sic]" - não apenas para os Ensinos Fundamental e Médio - para aqueles "interessados" que "demonstrem insuficiência de recursos", quando "houver instituições cadastradas", segundo "requisitos estabelecidos em lei".

Note-se que, nesse caso, não há qualquer restrição quanto ao tipo de escola, podendo ser, portanto, escolas privadas. Com esse novo texto, tanto a União quanto os estados, o Distrito Federal e os municípios deixam de ter a obrigação de expandir as suas redes nas localidades em que haja falta de vagas públicas, resultando na oferta, aos estudantes, de bolsas de estudo pagas com recursos públicos dos entes federados. Consequentemente, serão recursos públicos que passarão a ser dirigidos, num fluxo contínuo, para as escolas privadas.

Percebe-se, por toda a "trama" apresentada neste Editorial, que foi preponderante, em todo o processo de aprovação do Fundeb, a existência de uma forte mobilização social, a qual provocou reação favorável de Deputados Federais e Senadores para que não prosperassem as "ardilosas" estratégias governamentais na tentativa, primeiro, de desvincular os recursos constitucionais estabelecidos para a educação e para a saúde; 
depois, de associar parte dos recursos financeiros do Fundeb a um programa social do governo; e, finalmente, no estágio de regulamentação do fundo, para aprovar que a permissão para o setor privado comunitário, confessional ou filantrópico e o Sistema S poderem receber parte substancial dos recursos do Fundeb - cerca de R\$15,9 bilhões, conforme cálculo realizado pela Fineduca (FINEDUCA; CAMPANHA, 2020).

Nota-se, entretanto, que essa saga governamental para retirar recursos do fundo público associados à sua vertente social (OLIVEIRA, 1988) está tendo continuidade com a PEC n. 188/2019-Senado, a qual espera-se ser votada em 2021, o que exigirá, novamente, uma mobilização social ainda mais intensa para que não se concretize.

Há que se mencionar, também, a PEC n. 187/2019-Senado, que tem como proposta a extinção de todos os fundos infraconstitucionais, entre eles o Fundo Nacional de Desenvolvimento Científico e Tecnológico (FNDCT). Caso isso ocorra, será mais um estrangulamento no financiamento da ciência e da tecnologia no país (BRASIL, 2019a).

A tramitação para a aprovação da PEC n. 15/2015, que resultou na EC-108, e sua regulamentação, PL n. 4372, que se transformou na Lei n. 14.113, de 25 de dezembro de 2020, deixa-nos uma lição: serão necessárias muitas mobilizações para que a continuidade de desconstrução e desfazimento implementados pelo governo Bolsonaro seja bloqueada.

Em Editorial de 2016, quando discutíamos as iniciativas do governo Temer, intitulamo-lo “Tempos de Desconstrução e Resistência” às iniciativas de tal governo. Já antevíamos que elas eram "uma mostra de desafios a serem enfrentados no campo educacional" nos anos seguintes (EDITORIAL, 2016). Agora, em 2021, diante da confessa aversão ao texto constitucional de 1988 pelos grupos que assumiram o Governo Federal e da declaração do chefe de governo de que há que se descontruir e desfazer, não há mais que simplesmente resistir, como dizíamos em 2016, mas nos mobilizarmos para estabelecer um basta veemente a essa situação, para que não se comprometa ainda mais o futuro do Brasil!

\section{Referências}

AMADO, G. OAB processou governo Bolsonaro uma vez por semana nos dois primeiros anos. Época, 25 dez. 2020. Disponível em: https://epoca.globo.com/guilherme-amado/oab-processou-governo-bolsonarouma-vez-por-semana-nos-dois-primeiros-anos-24810000. Acesso em: 29 dez. 2020.

BRASIL. Presidência da República. Constituição da República Federativa do Brasil. Diário Oficial da União, Brasília, DR, 5 out. 1988. Disponível em: http://www.planalto.gov.br/ccivil_03/constituicao/constituicao.htm. Acesso em: 01 abr. 2020.

BRASIL. Lei n. 9.394, de 20 de dezembro de 1996. Estabelece as Diretrizes e bases da Educação Nacional. Brasília, DF: Presidência da República, 1996. Disponível em: http://www4.planalto.gov.br/legislacao. Acesso em: 28 nov. 2010.

BRASIL. Lei n. 11.494, de 20 de junho de 2007. Regulamenta o Fundo de Manutenção e Desenvolvimento da Educação Básica e de Valorização dos Profissionais da Educação - FUNDEB, de que trata o art. 60 do Ato das Disposições Constitucionais Transitórias; altera a Lei n.-10.195, de 14 de fevereiro de 2001; revoga dispositivos das Leis n. 9.424, de 24 de dezembro de 1996, 10.880, de 9 de junho de 2004, e 10.845, de 5 de março de 2004; e dá outras providências Brasília, DF: Presidência da República, 2007. Disponível em: http:// www.planalto.gov.br/ccivil_03/_ato2007-2010/2007/lei/111494.htm. Acesso em: 28 dez. 2020. 
BRASIL. Emenda Constitucional n. 59, de 11 de novembro de 2009. Acrescenta $\$ 3^{\circ}$ ao art. 76 do Ato das Disposições Constitucionais Transitórias para reduzir, anualmente, a partir do exercício de 2009, o percentual da Desvinculação das Receitas da União incidente sobre os recursos destinados à manutenção e desenvolvimento do ensino de que trata o art. 212 da Constituição Federal, dá nova redação aos incisos I e VII do art. 208, de forma a prever a obrigatoriedade do ensino de quatro a dezessete anos e ampliar a abrangência dos programas suplementares para todas as etapas da educação básica, e dá nova redação ao $\$ 4^{\circ}$ do art. 211 e ao $\$ 3^{\circ}$ do art. 212 e ao caput do art. 214, com a inserção neste dispositivo de inciso VI. Brasília, DF: Presidência da República, 2009. Disponível em: http://www.planalto.gov.br/ccivil_03/constituicao/ emendas/emc/emc59.htm. Acesso em: 30 dez. 2020.

BRASIL. Proposta de Emenda à Constituição n. 15, de 2015. Insere parágrafo único no art. 193; inciso IX, no art. 206 e art. 212-A, todos na Constituição Federal, de forma a tornar o Fundo de Manutenção e Desenvolvimento da Educação Básica e de Valorização dos Profissionais da Educação - Fundeb instrumento permanente de financiamento da educação básica pública, incluir o planejamento na ordem social e inserir novo princípio no rol daqueles com base nos quais a educação será ministrada, e revoga o art. 60 do Ato das Disposições Constitucionais Transitórias. Brasília, DF: Presidência da República, 2015. Disponível em: https:// www.camara.leg.br/proposicoesWeb/prop_mostrarintegra? codteor=1317615\&filename=PEC+15/2015. Acesso em: 22 dez. 2020.

BRASIL. Emenda Constitucional n. 95, de 15 de dezembro de 2016. Altera o Ato das Disposições Constitucionais Transitórias, para instituir o Novo Regime Fiscal, e dá outras providências. Brasília, DF: Presidência da República, 2016. Disponível em: http://www.planalto.gov.br/ccivil_03/constituicao/emendas/ emc/emc95.htm. Acesso em: 02 ago. 2020.

BRASIL. Proposta de Emenda à Constituição n. 187, de 2019. Institui reserva de lei complementar para criar fundos públicos e extingue aqueles que não forem ratificados até o final do segundo exercício financeiro subsequente à promulgação desta Emenda Constitucional, e dá outras providências. Brasília, DF: Senado Federal, 2019a. Disponível em: https://legis.senado.leg.br/sdleg-getter/documento?dm=8035576\&ts=16092 49578306\&disposition=inline. Acesso em: 02 jan. 2021.

BRASIL. Proposta de Emenda à Constituição n. 188, de 2019. Altera arts. $6^{\circ}, 18,20,29-\mathrm{A}, 37,39,48,62$, $68,71,74,84,163,165,166,167,168,169,184,198,208,212,213$ e 239 da Constituição Federal e os arts. 35, 107, 109 e 111 do Ato das Disposições Constitucionais Transitórias; acrescenta à Constituição Federal os arts. 135-A, 163-A, 164-A, 167-A, 167-B, 168-A e 245-A; acrescenta ao Ato das Disposições Constitucionais Transitórias os arts. 91-A, 115, 116 e 117; revoga dispositivos constitucionais e legais e dá outras providências. Brasília, DF: Senado Federal, 2019b. Disponível em: https://legis.senado.leg.br/sdleg-getter/documento?dm $=8035580 \&$ ts $=1576105226199 \&$ disposition=inline. Acesso em: 01 dez. 2020.

BRASIL. Emenda Constitucional n. 108, de 26 de agosto de 2020. Altera a Constituição Federal para estabelecer critérios de distribuição da cota municipal do Imposto sobre Operações Relativas à Circulação de Mercadorias e sobre Prestações de Serviços de Transporte Interestadual e Intermunicipal e de Comunicação (ICMS), para disciplinar a disponibilização de dados contábeis pelos entes federados, para tratar do planejamento na ordem social e para dispor sobre o Fundo de Manutenção e Desenvolvimento da Educação Básica e de Valorização dos Profissionais da Educação (Fundeb); altera o Ato das Disposições Constitucionais Transitórias; e dá outras providências. Brasília, DF: Presidência da República, 2020a. Disponível em: http:// www.planalto.gov.br/ccivil_03/constituicao/emendas/emc/emc108.htm. Acesso em: 30 dez. 2020. 
BRASIL. Lei n. 14.113, de 25 de dezembro de 2020. Regulamenta o Fundo de Manutenção e Desenvolvimento da Educação Básica e de Valorização dos Profissionais da Educação (Fundeb), de que trata o art. 212-A da Constituição Federal; revoga dispositivos da Lei n. 11.494, de 20 de junho de 2007; e dá outras providências. Brasília, DF: Presidência da República, 2020b. Disponível em: http://www.planalto. gov.br/ccivil_03/_Ato2019-2022/2020/Lei/L14113.htm\#: :text=LEI\%20N\%C2\%BA\%2014.113\%2C\%20 DE\%2025,2007\%3B\%20e\%20d\%C3\%A1\%20outras\%20provid\%C3\%AAncias. Acesso em: 30 dez. 2020.

BRASIL. Projeto de Lei n. 3076, de 2020. Institui o Programa Universidades e Institutos Empreendedores e inovadores - Future-se. Brasília, DF: Câmara dos Deputados, 2020c. Disponível em: https://www.camara. leg.br/proposicoesWeb/prop_mostrarintegra;jsessionid=DFCA3175741F98195C96284FD8FCDA2F.prop osicoesWebExterno2? codteor=1900012\&filename=PL+3076/2020. Acesso em: 3 set. 2020.

BRASIL. Projeto de Lei n. 4372, de 2020. Regulamenta o Fundo de Manutenção e Desenvolvimento da Educação Básica e de Valorização dos Profissionais da Educação - FUNDEB, de que trata o art. 212-A da Constituição Federal; e dá outras providências. Brasília, DF: Câmara dos Deputados, 2020d. Disponível em: https://www.camara.leg.br/proposicoesWeb/prop_mostrarintegra?codteor=1926034\&filename $=$ PL+4372/2020. Acesso em: 20 dez. 2020.

EDITORIAL E\&S. Tempos de Desconstrução e resistência. Educação \& Sociedade, Campinas, v. 37, n. 136, p. 591-597, 2016. https://doi.org/ 10.1590/ES0101-73302016v37n136ED

EDITORIAL E\&S. A educação no atual cenário político econômico mundial: a disputa eleitoral e os retrocessos na educação. Educação \& Sociedade, Campinas, v. 39, n. 144, p. 515-521, 2018. https://doi. org/10.1590/es0101-73302018v38n144ED

EDITORIAL E\&S. Reafirmar a defesa do sistema de ciência, tecnologia e ensino superior público brasileiro. Educação \& Sociedade, Campinas, v. 40, e0230375, 2019. https://doi.org/10.1590/ES0101-73302019230375

FERNANDES, A.; FUCS, J.; AGOSTINI, R. “Os políticos tem que controlar 100\% do orçamento”. Entrevista de Paulo Guedes. Estadão, São Paulo, 10 mar. 2019. Economia. Disponível em: https://economia.estadao.com. br/noticias/geral,os-politicos-tem-de-controlar-100-do-orcamento,70002749472. Acesso em: 22 dez. 2020.

FINEDUCA; CAMPANHA NACIONAL PELO DIREITO À EDICAÇÃO. Nota Técnica. PL da Câmara sobre o Fundeb: retirando recursos de Estados, DF e Municípios e rasgando a Constituição. São Paulo: Fineduca, 2020. Disponível em: https://fineduca.org.br/wp-content/uploads/2020/12/PautasPoliticas_ Fundeb2020_NotaTecnica_2020_12_14_Campanha-Fineduca_final.pdf. Acesso em: 20 dez. 2020.

GIMENES, E. Governo tenta repartir Fundeb para usar em "voucher-creche"; votação muda para terça. Brasil de Fato, Brasília, DF, 20 jul. 2020. Disponível em: https://www.brasildefato.com.br/2020/07/20/ governo-tenta-repartir-fundeb-para-usar-em-voucher-creche-votacao-muda-para-terca. Acesso em: 21 dez. 2020.

LÁZARO, N. “Temos que desconstruir muita coisa”, diz Bolsonaro sobre o Brasil, Metrópoles, 18 mar. 2019. Política. Disponível em: https://www.metropoles.com/mundo/politica-int/temos-que-desconstruirmuita-coisa-diz-bolsonaro-sobre-brasil. Acesso em: 20 nov. 2020.

LEHER, R. Apontamentos para análise da correlação de forças na educação brasileira: em prol da frente democrática. Educação \& Sociedade, Campinas, v. 40, 2019. https://doi.org/10.1590/ ES0101-73302019219831 
NOGUEIRA, M. A. O que motiva os ataques dos bolsonaristas ao chamado “marxismo cultural”. Época, 25 jan. 2019. Disponível em: https://epoca.globo.com/o-que-motiva-os-ataques-dos-bolsonaristas-ao-chamadomarxismo-cultural-23376168. Acesso em: 30 dez. 2020.

OLIVEIRA, F. Os direitos do antivalor: a economia política da hegemonia imperfeita. Petrópolis: Vozes, 1988.

PINTO, E. G.; XIMENES, S. B. Financiamento dos direitos sociais na Constituição de 1988: do "pacto assimétrico" ao "estado de sítio fiscal”. Educação \& Sociedade, Campinas, v. 39, n. 145, p. 980-1003, dez. 2018. Disponível em: http://www.scielo.br/scielo.php?script=sci_arttext\&pid=\$0101-73302018000400980\&lng=e n\&nrm=iso. Acesso em: 14 jan. 2021.

PINTO, E. G. et al. Nota técnica sobre a destinação privada dos recursos do Fundeb e oferta irregular de ensino. 13 dez. 2020. Disponível em: https://portal.tce.go.gov.br/documents/129288/312556/Nota\%20 T\%C3\%A9cnica\%20sobre\%20a\%20destina\%C3\%A7\%C3\%A3o\%20privada\%20dos\%20recursos\%20do\%20 FUNDEB\%20e\%20oferta\%20irregular\%20de\%20ensino/392f0b8e-45be-43cf-92d8-96e869849aed. Acesso em: 30 dez. 2020.

PROGRAMA DE GOVERnO BOLSONARO. O Caminho da Prosperidade, 2018. Disponível em: https:// veja.abril.com.br/wp-content/uploads/2018/10/plano-de-governo-jair-bolsonaro.pdf. Acesso em: 27 dez. 2020.

TEIXEIRA, A. Bases preliminares para o plano de educação referente ao Fundo Nacional de Ensino Primário. Revista Brasileira de Estudos Pedagógicos, Rio de Janeiro, v. 38, n. 88, p. 97-107, out./dez. 1962.

Recebido: 18 jan. 2021

Aceito: 18 jan. 2021 